\title{
Marcelo Starcenbaum ${ }^{1}$
}

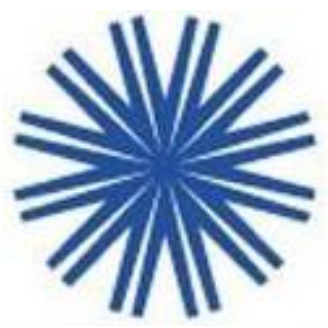

Puede resultar iluminador caracterizar al reciente libro de Jaime Ortega Reyna como el resultado de un cruce productivo entre dos campos de investigación. Por un lado, los estudios althusserianos, espacio en el cual se despliegan análisis de distintos aspectos relativos a la obra del marxista francés. Por el otro, la historia intelectual de las izquierdas latinoamericanas, la cual busca dotar de espesor histórico las ideas forjadas por personas y colectivos situados en el margen izquierdo de la cultura política de la región. Ambos campos, en los cuales el autor del libro ha tenido intervenciones destacadas, han sufrido una notable transformación en los últimos veinte años. En el caso del primero, los análisis sobre la tradición althusseriana ha tendido a despegarse del enjuiciamiento para acercarse a la lectura crítica. En el caso del segundo, las reconstrucciones han suspendido las acusaciones que replicaban las querellas de la izquierda partidaria para avanzar hacia una comprensión histórica de los sujetos y sus ideas. En su reconstrucción de la circulación y apropiación de las ideas althusserianas en diversos ámbitos intelectuales y políticos de América Latina, La incorregible imaginación avanza tanto en una recuperación crítica de una de las formas en las que se desenvolvió la corriente althusseriana como en una revisión de los modos en los que militantes e intelectuales de la región acudieron a Althusser en pos de desarrollar posiciones renovadoras en el seno de los espacios que ocupaban. A través de un diálogo con la bibliografía ya existente en ambos campos de investigación, el trabajo de Ortega Reyna brinda una visión panorámica a la vez que detallada de los canales a través de los cuales la obra de Althusser prolongó sus efectos, de manera fiel pero también siendo traicionada por sus lectores, en la diversidad y la complejidad del escenario intelectual y político latinoamericano

Tanto la Introducción al libro, escrita por el propio autor, como el prólogo, redactado por el joven intelectual mexicano Víctor Hugo Pacheco Chávez, permiten adentrarnos en las motivaciones políticas y teóricas que se encuentran por detrás de este ejercicio de

\footnotetext{
${ }^{1}$ Universidad Nacional de la Plata, Argentina. E-mail: mstarcenbaum@unp.ar
} 
reconstrucción de los itinerarios de Althusser en América Latina y el Caribe. Algunas de estas motivaciones aparecen claramente explicitadas en estos textos introductorios. Ortega Reyna inscribe su trabajo en el fenómeno global de recuperación crítica del legado althusseriano. En este sentido, su investigación integra una serie de ejercicios que en los últimos quince años se dedicaron a restituir al althusserianismo como corriente político-intelectual. Alejados de las propias polémicas que marcaron el despliegue de la tradición inaugurada por Althusser, todos estos trabajos se proponen una tarea de recolocación de la obra del marxista francés en los avatares políticos e intelectuales de la segunda mitad del siglo XX. De este modo, el autor hace participar a su libro de un conjunto de iniciativas, entre las que cabe destacar la aparición de revistas dedicadas íntegramente al pensamiento althusseriano, la realización de eventos dedicados a su obra y el trabajo individual de autores que se han dedicado en los últimos años a la consolidación de los estudios althusserianos. Ortega Reyna no sólo constata la existencia de una nueva oleada de investigaciones sobre Althusser, sino que además da lugar a una interesante reflexión acerca de los elementos que la componen. Según su perspectiva, en este reencuentro con Althusser convergen la superación del silencio de la década de 1990, el retorno a uno de los autores que sentaron las bases del posmarxismo, la lectura cruzada con otros nombres del pensamiento contemporáneo, y el interés por los mecanismos de difusión de su obra en distintos espacios geográficos. Junto a estas reflexiones explícitas de alcance global y latinoamericano, las palabras del prologuista nos permiten calibrar las implicaciones de un regreso a Althusser en el contexto mexicano. De la elogiosa presentación que hace Pacheco Chávez se desprende que el trabajo de Ortega Reyna interrumpe dos movimientos tendientes a la clausura del pensamiento althusseriano. Uno de ellos tiene que ver con la fuerte presencia en el marxismo mexicano de dos orientaciones contradictorias con el althusserianismo: la filosofía de la praxis, representada en la obra de Adolfo Sánchez Vázquez, y la crítica de la economía política, condensada en el trabajo de Bolívar Echeverría. El otro, está relacionado con el giro conservador de gran parte de la intelectualidad de izquierdas mexicana, lo cual ha tenido como uno de sus efectos la negación y la ridiculización de las discusiones teóricas desarrolladas en las décadas de 1960 y 1970. La contextualización de la recuperación del althusserianismo en la compleja historia del marxismo mexicano nos deja ver que el libro de Ortega Reyna representa un ejercicio de investigación tan justo como necesario.

Si bien enmarcada en un movimiento general de recolocación de la figura de Althusser, la intervención de Ortega Reyna se despliega sobre una serie de supuestos que tienden a volverla singular. Aunque remiten a distintos aspectos teóricos y metodológicos del abordaje de su 
objeto de estudio, los supuestos que guían la investigación tienen en común un anclaje latinoamericano. Por un lado, el libro propicia una interesante reflexión acerca de la categoría de "althusserianismo". Luego de presentar de manera somera pero precisa el despliegue de la intervención althusseriana en Francia, Ortega Reyna afirma que la recepción de Althusser en América Latina constituyó un fenómeno diverso y polimórfico. En este sentido, la categoría de "althusserianismo" tendría un efecto más de bloqueo que de iluminación sobre una diversidad de recepciones desplegadas en la complejidad histórica y social del subcontinente. Bajo unas condiciones específicas, entre las que cabe citar la revolución cubana, la deslegitimación de los partidos comunistas y la formación de grupos armados, la circulación de Althusser en América Latina dio lugar a una serie de apropiaciones múltiples y diversas. Más que recuperar un "althusserianismo", el recorrido esté orientado hacia la delimitación de la difusión de Althusser en la región como el elemento propiciatorio de un nuevo modo de pensar. Si bien las recepciones latinoamericanas de Althusser tuvieron en común la apelación a los elementos característicos de la obra del pensador francés, todas ellas llevaron a cabo ejercicios de traducción tan singulares que resultaría forzoso agruparlas en una misma categoría o etiqueta. Por ello, la recuperación de cada una de estas recepciones está mediada por la noción de efecto. Es decir, que más allá de que la obra de Althusser haya sido aceptada, rechazada o incorporada parcialmente, lo que generó su recepción fue la aparición de un nuevo campo teórico. A partir de Althusser fue posible pensar de una manera distinta problemas acuciantes de la práctica intelectual como la relación entre teoría y política o el vínculo entre conceptos y problemas. Por otra parte, este rodeo latinoamericano habilita una complejización de la pertenencia del althusserianismo a la tradición del marxismo occidental. La recuperación de las apropiaciones de Althusser realizadas en el marco de potentes movimientos políticos y culturales latinoamericanos permite un cuestionamiento de la tesis andersoniana del marxismo occidental como una tradición teórica escindida de la práctica política transformadora.

A partir de estos supuestos, los capítulos del libro de Ortega Reyna recorren los diferentes aspectos relativos a los itinerarios de Althusser en la cultura política latinoamericana de las décadas de 1960, 1970 y 1980. Este recorrido es desagregado por el autor a partir de dos herramientas analíticas proporcionadas por la historia intelectual. La primera de ellas remite a la dimensión cultural de los fenómenos de circulación intelectual y consiste en la indagación sobre de los soportes materiales a partir de los cuales se difunden las ideas. En este caso el autor analiza los libros, las revistas y las editoriales a través de los cuales la obra de Althusser se propagó en los diversos países latinoamericanos. Reponiendo un contexto político e 
intelectual signado por los efectos del XX Congreso del PCUS, la revolución cubana y el '68 global, Ortega Reyna se detiene en un segmento publicaciones latinoamericanas que difundieron a Althusser en el marco de una modernización de la cultura política de izquierdas en la región. De esta manera son analizados los diversos procesos de traducción y difusión de Althusser en las revistas cubanas Pensamiento crítico y Lecturas de filosofía, las colombianas Ideas y valores y ECO, las argentinas Pasado y presente y Los libros y las mexicanas Dialéctica, Historia y sociedad y Cuadernos políticos. El otro nivel a través del cual el autor lleva a cabo este recorrido está recortado estrictamente al plano de las ideas y busca dar cuento de los efectos de la recepción de un pensamiento en un contexto histórico determinado. Volviendo de igual a modo a situar estos efectos en el marco de un proceso regional de modernización y radicalización, Ortega Reyna se concentra en las demarcaciones que diferentes intelectuales latinoamericanos desarrollaron al amparo de las tesis althusserianas. Así se recorren las producciones de Martínez Heredia en Cuba, de José Aricó, Oscar del Barco, Saúl Karsz, Mauricio Malamud y Emilio de Ípola en Argentina, de Enrique González Rojo, Raúl Olmedo, Carlos Pereyra y Fernanda Navarro en México, Tomás Moulián, Sergio Ramos Córdova, Tomás Vasconi y Carlos Cerda en Chile, Eudoro Rodríguez Albarracín, Enrique Orozco Silva y Freddy Téllez en Colombia, y Rigoberto Lanz y José Rafael Núñez Tenorio en Venezuela.

Digamos, por último, que las recepciones latinoamericanas de Althusser constituyen un espacio virtualmente inabarcable. Traducciones, ediciones, viaje de estudios, intercambios epistolares, apropiaciones y lecturas cruzadas con otros autores forman un corpus documental de tal magnitud que quien se enfrenta a su reconstrucción es empujado necesariamente a operaciones de recorte y jerarquización. Es éste el camino por el cual se desenvuelve el recorrido emprendido por Ortega Reyna. Enfrentado a la vastedad de los materiales, el autor ha priorizado destacar algunos de los aspectos más originales de la recepción latinoamericana de Althusser. De esta manera dedica el último capítulo del libro a una reconstrucción de las relaciones entre la obra de Althusser y las experiencias de lucha armada en la región. En lo que es denominado como "una trama compleja en tres tramos", el autor analiza el trabajo realizado por Régis Debray al calor del proceso revolucionario cubano, el llevado a cabo por Mauricio Malamud en el contexto de crisis del Partido Comunista Argentino a mediados de la década de 1960, y las producciones de Marta Harnecker en el marco del surgimiento de organizaciones guerrilleras centroamericanas en la década de 1980. Del mismo modo, el autor confiesa que se ha visto obligado a relegar otros aspectos no menos relevantes de los itinerarios 
latinoamericanos de Althusser, tales como la vasta recepción en Brasil o el abultado espectro de lecturas anti-althusserianas. Lejos de tratarse de una limitación, las opciones tomadas por Ortega Reyna constituyen operaciones interpretativas acordes a la amplitud del objeto de estudio. Puede afirmarse, en suma, que la minuciosidad del recorrido por las formas en las que el pensamiento de Althusser fue difundido y apropiado, así como el piso interpretativo brindado por el libro para las investigaciones ulteriores que cubran los problemas que no fueron abordados, hacen de La incorregible imaginación un aporte significativo tanto en el campo de los estudios althusseriano como en el de la historia intelectual de las izquierdas latinoamericanas. 